\title{
Water dynamics at the urban soil-atmosphere interface-rainwater storage in paved surfaces and its dependence on rain event characteristics
}

\author{
Thomas Nehls $^{1,2} \cdot$ Andre Peters $^{1,3} \cdot$ Fabian Kraus $^{1,4} \cdot$ Yong Nam Rim ${ }^{1}$ \\ Received: 6 January 2020 / Accepted: 17 August 2020 / Published online: 28 August 2020 \\ (C) The Author(s) 2020, corrected publication 2020
}

\begin{abstract}
Purpose The surface store governs the rainwater partition, e.g., water storage and evaporation on paved surfaces, especially for low-intensity and low-sum rain events, which account for the greatest part of the total rainfall in a temperate climate city like Berlin, Germany. The surface store $S$ is a fixed value, dependent on surface relief and pore system characteristics. Contrary, in this study, the surface storage was assumed to depend also on the rain intensity, thus being variable from event to event.

Materials and methods The surface store filling dynamics for dense (DP), porous (PP), and highly infiltrative (IP) paving materials were studied in a rainfall simulator. Irrigation intensities $p$ ranged from 0.016 to $0.1 \mathrm{~mm} \mathrm{~min}{ }^{-1}$ which represent the 25 to $88 \%$ quantiles of the rain event distribution in Berlin, Germany (1961 to 1990).

Results and discussion Three surface stores can be separated: storage until initial runoff, $S_{\mathrm{f}}$, at maximum filling, $S_{\mathrm{m}}$, and for steady-state runoff, $S_{\mathrm{eq}}$-all of them can be regarded as effective stores depending on the aim of its use. The equilibrium store varies from 0.2 to $3 \mathrm{~mm}$ for DP, PP, and IP for the investigated rainfall intensities.

Conclusions For all pavers, the surface store depends on rainfall intensity, which was shown experimentally and confirmed by numerical simulation of the infiltration. We introduce a simple and robust method to describe $S_{\mathrm{f}}, S_{\mathrm{m}}=f(p)$ for different pavers. Pavers can evaporate a multiple of their surface store per day, depending on the rainfall distribution, which implicates the need for high temporal resolutions in urban hydrology modeling. Pavers can evaporate a multiple of their surface store per day, depending on the rainfall distribution. That implicates the need for high temporal resolutions in urban hydrology modeling.
\end{abstract}

Keywords Evaporation $\cdot$ Paved soils $\cdot$ Paving material $\cdot$ Precipitation intensity $\cdot$ Surface store $\cdot$ Water storage

Responsible editor: Kye-Hoon John Kim

Thomas Nehls

thomas.nehls@tu-berlin.de

1 Chair of Soil Conservation, Technische Universität Berlin, Ernst-Reuter-Platz 1, 10587 Berlin, Germany

2 Chair of Ecohydrology and Landscape Assessment, Technische Universität Berlin, Ernst-Reuter-Platz 1, 10587 Berlin, Germany

3 Institute for Geoecology, Division of Soil Science and Soil Physics, Technische Universität Braunschweig, Langer Kamp 19c, 38106 Braunschweig, Germany

4 Kompetenzzentrum Wasser Berlin gGmbH, Cicerostrasse 24, 10709 Berlin, Germany

\section{Introduction}

Urban areas have open soils and sealed and partially sealed soils, also called paved soils, impervious pavements, or porous pavements. Paved soils, impervious or pervious, account for large proportions of urban surfaces. In Berlin, they make two-thirds of the whole overbuild area. The water budget of these paved soils differs from natural soils; i.e., infiltration and evaporation are much smaller and thus, surface runoff is higher (Wessolek and Facklam 1997). The imbalanced water budget leads to ecological problems in the city. Runoff leads to the eutrophication of surface waters due to the first flush effects and combined sewer overflows (Heinzmann 1998). The relatively small amount of available water for evaporation is one cause for overheating of city centers (Oke 1982).

Consequently, a paradigm change in urban rainwater management from fast water removal towards storage leading to 
infiltration and evaporation was suggested (e.g., Field et al. 1982). Although increasing infiltration through permeable pavements is currently referred to as the "best practice," it cannot be the sole measure for good water management in urban areas. Many cities already observe rising groundwater levels due to increased infiltration and decreased water demand per capita. This can cause severe damage to buildings and infrastructures (Goebel et al. 2007) as well as increased leaching from vadose zone contaminations. An increased infiltration would also bear the risk of groundwater contamination due to recent emissions (Nehls et al. 2008). Furthermore, the water is needed at the surface rather than in the ground for other uses such as evaporative cooling. Namely, several cities need to adapt to climate change and to mitigate heat stress and the urban heat island. This requires adapted surface water stores (Nakayama and Fujita 2010; Starke et al. 2010).

The surface store or surface storage capacity is the maximum volume, which can be filled with water at the pavement surface and which is therefore not contributing to surface runoff (McGraw-Hill 2002). The surface storage in turn denotes the actual filling status of that volume and thus is dependent on the rain events and the general weather conditions.

In urban areas, the total precipitation $P(\mathrm{~mm})$ in a given time span is partitioned into the components surface runoff (including water flowing into sewer canals) $R(\mathrm{~mm})$, evaporation $E(\mathrm{~mm})$, infiltration into underlying soil $I(\mathrm{~mm})$, and storage in the surface store $S_{\text {tot }}(\mathrm{mm})$, leading to the following urban water balance equation:

$P=R+E+I+S_{\text {tot }}$

In order to adequately quantify the different terms of the water budget, it is necessary to know the quantities of the different components as well as the transmission rates between them. To do so, engineering-type maximum approximations (e.g., maximum storage capacity, maximum removal by drainage system) based on stormwater events are inappropriate. Instead, new process-based model approaches are needed, which predict all terms of the water budget for storm events, but also for medium and small rain events. One task to achieve that goal is to precisely know the quantity of the surface storage, where the water is retained after precipitation events for subsequent evaporation. Especially for small rain events, the runoff generation from pavements strongly depends on the amount of water which can be stored on and on the surface, as this water can infiltrate or evaporate from the surface (Mansell and Rollet 2009).

Whether the water stored at the surface may contribute to infiltration depends on the pavement design (sealed, partially sealed, pavement joint fraction) and the subsurface characteristics (Mansell and Rollet 2009). Usually, the surface store is regarded as a fixed value, dependent on surface relief, and porous material characteristics. Contrary to that assumption, we show that the effective storage for water at and near the surface is a process function dependent on material properties as well as on meteorological conditions, and thus, it is time variable.

In general, the surface store of pavement is built of (i) water held in its porous system by capillary and adsorptive forces and (ii) free water on the surface.

The storage of free water can take place in macroscopic surface depressions (puddles), pavement joints, and small depressions in the pavement material (coarse surface roughness). Such storing is not rate limited; the maximum store is a constant value. According to Jarvis (2007), water held at tensions greater than $6 \mathrm{~cm}$ water column can be regarded as free water. This corresponds to pores greater than $0.5 \mathrm{~mm}$ in diameter. Nehls et al. (2015) found $\sim 1 \mathrm{~mm}^{3}$ to be the smallest micro-relief feature still detectable by a terrestrial laser scanning method and regarded a pore diameter of $1 \mathrm{~mm}$ as an operational limit for free water. According to this, structures smaller than $1 \mathrm{~mm}$ in diameter can be treated as a porous system.

The porous system builds the second part of the surface store. It comprises the porosity of the paving materials, the joint fillings, and optionally the subsoil until the groundwater. Obviously, the surface store depends on the depth which is still considered as "surface." As a proposed operational measure, the surface depth is the thickness of the paving materials, excluding the subsoil. Although the subsoil can influence the precipitation partitioning for low-intensity rainfall, in this study, we will focus on the pavement. That is because the pavement system and subsoil are mostly hydraulically separated by a coarse-grained sublayer. Water, which entered the subsoil, will not evaporate from the paver surface. Also, the soil below the pavement layer can be described by traditional models.

Different from the depression store of the pavement, the filling of the porous system is limited by its maximum infiltration rate. The maximum infiltration rate depends on the hydraulic properties of the system, i.e., hydraulic conductivity and water retention characteristics and on the initial water content. If the rainfall rate exceeds the maximum infiltration rate, runoff is generated, although the surface store might still be filled. Thus, we regard the effective surface store as a time variable quantity depending on initial and boundary conditions. From this point of view, the total effective surface store $\left(S_{\text {tot }}(\mathrm{mm})\right)$ can be expressed as:

$S_{\mathrm{tot}}=S_{\mathrm{d}}+S_{\mathrm{ps}}$

where $S_{\mathrm{d}}(\mathrm{mm})$ is the depression store and $S_{\mathrm{ps}}(\mathrm{mm})$ is the pore system store. $S_{\mathrm{ps}}$ can be further sub-divided to $S_{\mathrm{ps}}=S_{\mathrm{ps}, \mathrm{p}}$ $+S_{\mathrm{ps}, \mathrm{j}}+S_{\mathrm{ps}, \mathrm{s}}$, where the subscripts $\mathrm{p}, \mathrm{j}$, and $\mathrm{s}$ indicate the paver block, the pavement joints, and the subsoil, respectively. In this study, we focus on $S_{\mathrm{ps}, \mathrm{p}}$ and on $S_{\mathrm{d}}$ as far as it is a characteristic of the paver itself.

Given its importance for its water balance, the systematic knowledge on the surface store of pavements is surprisingly 
small. Specialist experience and rule of thumb values are employed in practice but are rarely discussed scientifically nor measured directly yet.

Ramier et al. (2006) compared the runoff generation of two asphalt streets for 38 months and derived different runoff coefficients depending on precipitation and evaporation. They also estimated the surface stores of the two streets to be $1 \mathrm{~mm}$ and $3 \mathrm{~mm}$ by calibration of a model. Unfortunately, infiltration through cracks could not be excluded due to the given experimental design. Nehls et al. (2011) quantified the maximum surface store of a concrete slab pavement to $1.7 \mathrm{~mm}$ from lysimeter studies. Nehls et al. (2015) used a terrestrial laser scanning-based method to quantify the depression store of ideally constructed pavements to range from 0.07 to $1.4 \mathrm{~mm}$.

However, the surface store of pavement materials has not been directly investigated, separately from the pavement design; thus, it was influenced by depression store, slope, soil pore system, and infiltration or evaporation.

\subsection{Aims of the study}

In this study, we analyze the dynamics of the effective surface store for different pavers depending on typical rainfall intensities. Therefore, the rain events in Berlin (1961-1990) are analyzed for their event intensity and event sum distribution functions in order to identify representative rainfall intensities. The storage dynamics are then recorded for different pavers and the identified representative rainfall intensities. Three different representative paver types are studied: dense pavers (DP) without a noteworthy porosity, porous pavers (PP) which can be expected to store water in their pores, and a modern paver optimized for infiltration (IP).

\section{Materials and methods}

\subsection{Distribution of precipitation event sums and intensities}

Precipitation data for Berlin-Neukölln, provided in a resolution of $0.01 \mathrm{~mm}$ and $5 \mathrm{~min}$ for the years 1961 to $1990 \mathrm{DWD}$ (online) Deutscher Wetterdienst, have been investigated for typical precipitation event sums and intensities. Individual events have been separated by periods of at least $10 \mathrm{~min}$ without precipitation $(<0.01 \mathrm{~mm}$ in $10 \mathrm{~min})$. Using this minimum inter-event time, we separated $N=11363$ events and calculated the precipitation event sum $(P)$ and the average precipitation event intensity $(p)$, calculated as the event sum divided by the event duration, as well as their contribution to the cumulative sum of precipitation in the period (Fig. 1).

\subsection{Paving materials}

Three different pavers were analyzed in this study: a dense paver with low porosity (DP), a porous paver with relatively high porosity (PP), and a porous paver optimized for infiltration with large pores (IP). The investigated pavers are all made of concrete but differ in porosity and sizes (Table 1, Fig. 2). They represent typical paving materials which are widely used in urban areas. The DP slabs are widely used in old inner-city parts. The PP slabs are recently used for sidewalk construction and are found in the younger parts of cities. The modern IP slabs are increasingly used in new single-detached housing areas and are advertised as "ecologic."

Cylinders with a cross-sectional area of $2500 \mathrm{~mm}^{2}$ have been cut from the pavers for a general characterization of the materials. The dry bulk density and solid density (helium pycnometry) were determined. The field capacity $\left(\theta_{\mathrm{pF}}=1.8\right)$ was measured using the porous plate method, while the saturated hydraulic conductivity $\left(K_{\text {sat }}\right)$ was measured using the constant head permeability test. The physical properties are listed in Table 1.

\subsection{Experimental setup}

In order to quantify the dynamic surface store, rainfall simulation experiments were carried out with de-ionized water. The experimental setup consisted of a plexiglass box in which the pavers (for dimensions, see Table 1) were irrigated from a $380 \times 380 \mathrm{~mm}$ needle irrigator with 400 needles (Fig. 3) connected to Mariott's bottle, with which the irrigation intensities $(p)$ varying from 0.02 to $0.1 \mathrm{~mm} \mathrm{~min}^{-1}$ were adjusted. The height of the fall for the "raindrops" was $400 \mathrm{~mm}$ sufficient for bursting drops at the paving slabs. The irrigation box was sealed against the outer atmosphere in order to prevent evaporation out of the box. Temperature and humidity have been monitored (hytemod by B+B Thermo Technik, Donaueschingen, Germany) during the experiment. The loss of water from the pavers' surface by evaporation did not exceed $0.005 \mathrm{~mm}$ per experiment, which is less than $1 \%$ compared with the smallest measured surface store.

Three replicates of oven-dried $(333 \mathrm{~K}$ until constant weight) pavers rested horizontally on a digital balance with 0.05-g resolution (Kern 572, Kern \& Sohn, BalingenFrommern, Germany) and were irrigated from the needle irrigator. The time of the first runoff, maximum filling, and the steady-state runoff rate was identified.

\subsection{Simulations}

In order to theoretically investigate the dynamics of store filling, a simulation study was conducted. Therefore, the HYDRUS 1D code was used which solves the Richards equation numerically (Simunek et al. 2008). These simulations have been done in order to compare theoretical and 


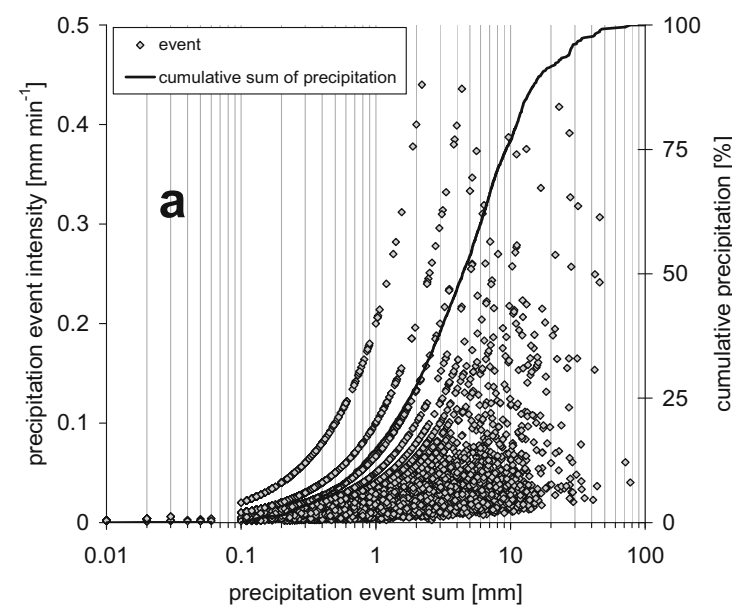

Fig. 1 a Precipitation events (squares) according to their event sum and intensity with the cumulative precipitation (solid line) in relation to the event sum distribution; b precipitation events (squares) according to their event intensity and sum with the cumulative precipitation (solid line) in

experimental infiltration dynamics qualitatively for the porous paver as it was the only material showing a dynamic behavior (Table 2). Its hydraulic characteristics were described using the Fayer and Simmons (1995) retention model modified by Peters et al. (2011) combined with the conductivity model of Mualem (1976). The Fayer and Simmons model explicitly accounts for absorptive water in the dry range, which is important for simulation of infiltration into initially dry materials. The slight modification of Peters et al. (2011) assures the monotonicity of the Fayer and Simmons model. The complete retention function is given by:

$\theta(h)= \begin{cases}\theta_{\mathrm{a}} \chi+\left(\theta_{\mathrm{m}}-\theta_{\mathrm{a}} \chi\right)\left[1+(\alpha h)^{n}\right]^{n-1 / n} & \text { for } h<h_{\mathrm{u}} \\ \theta_{\mathrm{s}} & \text { for } h \geq h_{\mathrm{u}}\end{cases}$

with

$\chi=\left(1-\frac{\ln (h)}{\ln \left(h_{0}\right)}\right)$

and

$\theta_{\mathrm{m}}=\theta_{\mathrm{a}} \chi+\frac{\theta_{\mathrm{s}}-\theta_{\mathrm{a}} \chi}{\left[1+\left(\alpha h_{\mathrm{u}}\right)^{n}\right]^{n-1 / n}}$

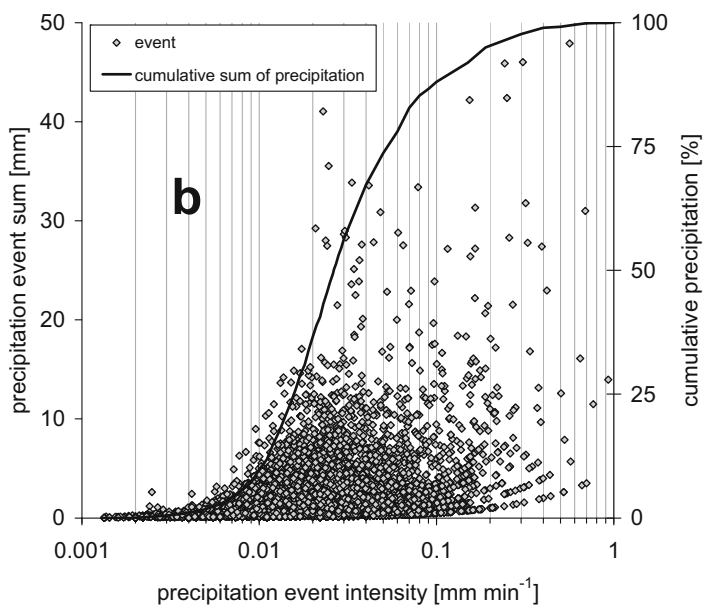

relation to the event intensity. Precipitation data for the station BerlinMarienfelde, Germany (1961-1990, resolution $0.1 \mathrm{~mm}$ per $5 \mathrm{~min}$ ). Event separation was performed using the minimum inter-event time of $10 \mathrm{~min}$ $(N=11363)$

where $n(-)$ and $\alpha\left(\mathrm{cm}^{-1}\right)$ are curve shape parameters, $h_{0}$ $(\mathrm{cm})$ is the matric head at a water content of zero here set to $10^{6.8}(\mathrm{~cm})$, which equals oven dryness at typical laboratory environment, $\theta_{\mathrm{s}}\left(\mathrm{m}^{3} \mathrm{~m}^{-3}\right)$ is the saturated water content, and $\theta_{\mathrm{m}}\left(\mathrm{m}^{3} \mathrm{~m}^{-3}\right)$ is a fictitious parameter slightly greater than $\theta_{\mathrm{s}}$, adopted from the retention model of Vogel et al. (2001). $\theta_{\mathrm{a}}$ $\left(\mathrm{m}^{3} \mathrm{~m}^{-3}\right)$ is the water content of the absorptive part at $h=1$ and $h_{\mathrm{u}}(\mathrm{cm})$ is the matric head above which the soil must be saturated here set to $h_{\mathrm{u}}=1 \mathrm{~cm}$. The hydraulic conductivity was predicted from the retention function by numerically solving the capillary bundle model of Mualem (1976):

$K(F)=K_{\text {sat }} F^{0.5}\left[\frac{\int_{0}^{F} \frac{1}{h(x)} d x}{\int_{0}^{1} \frac{1}{h(x)} d x}\right]^{2}$

where $K_{\text {sat }}\left(\mathrm{cm} \mathrm{d}^{-1}\right)$ is the saturated conductivity, $F(-)$ is the saturation, defined here as $\theta / \theta_{\mathrm{s}}$, and $x$ is a dummy variable of integration.

The free adjusted hydraulic parameters $\left(\alpha, n\right.$, and $\left.\theta_{\mathrm{a}}\right)$ were chosen in a way that the measured quantities for PP given in Table 1 are met. The shape of the resulting water retention and conductivity curves resemble the shape of the more recently published Peters-Durner-Iden models (Peters, 2013,2014;
Table 1 Physical characteristics of the investigated concrete pavers

\begin{tabular}{lccc}
\hline & Dense paver (DP) & Porous paver (PP) & Infiltration paver (IP) \\
\hline Dimensions x, y, z (m) & $0.35,0.35,0.06$ & $0.3,0.3,0.05$ & $0.195,0.195,0.025$ \\
Particle density $\left(\mathrm{kg} \mathrm{m}^{-3}\right)$ & 2535 & 2611 & 2634 \\
Bulk density $\left(\mathrm{kg} \mathrm{m}^{-3}\right)$ & 2376 & 2331 & 2118 \\
Porosity $\left(\mathrm{m}^{3} \mathrm{~m}^{-3}\right)$ & 0.06 & 0.11 & 0.20 \\
$\Theta_{\mathrm{pF}}=1.8\left(\mathrm{~m}^{3} \mathrm{~m}^{-3}\right)$ & 0.05 & 0.09 & 0.08 \\
$K_{\mathrm{sat}}\left(\mathrm{mm} \mathrm{min}^{-1}\right)$ & 0.001 & 0.005 & 9.9 \\
\hline
\end{tabular}


Fig. 2 Paving materials investigated in this study DP) dense paver; PP) porous paver; IP. a porous paver optimized for infiltration seen from above, IP $\mathbf{b}$ macro - pores seen from the bottom side
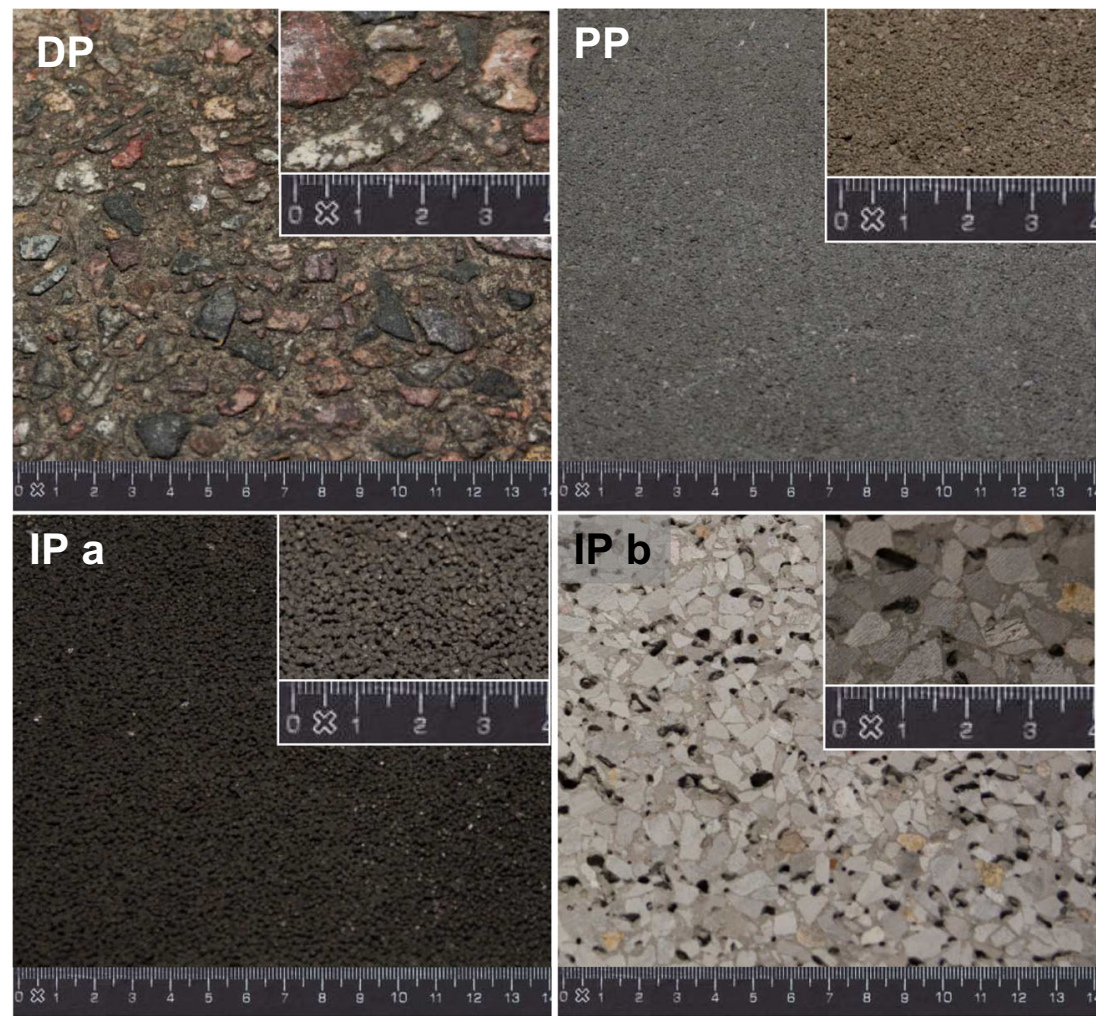

Iden and Durner, 2014), which explicitly distinguish between water storage and conductivity in capillaries and films and

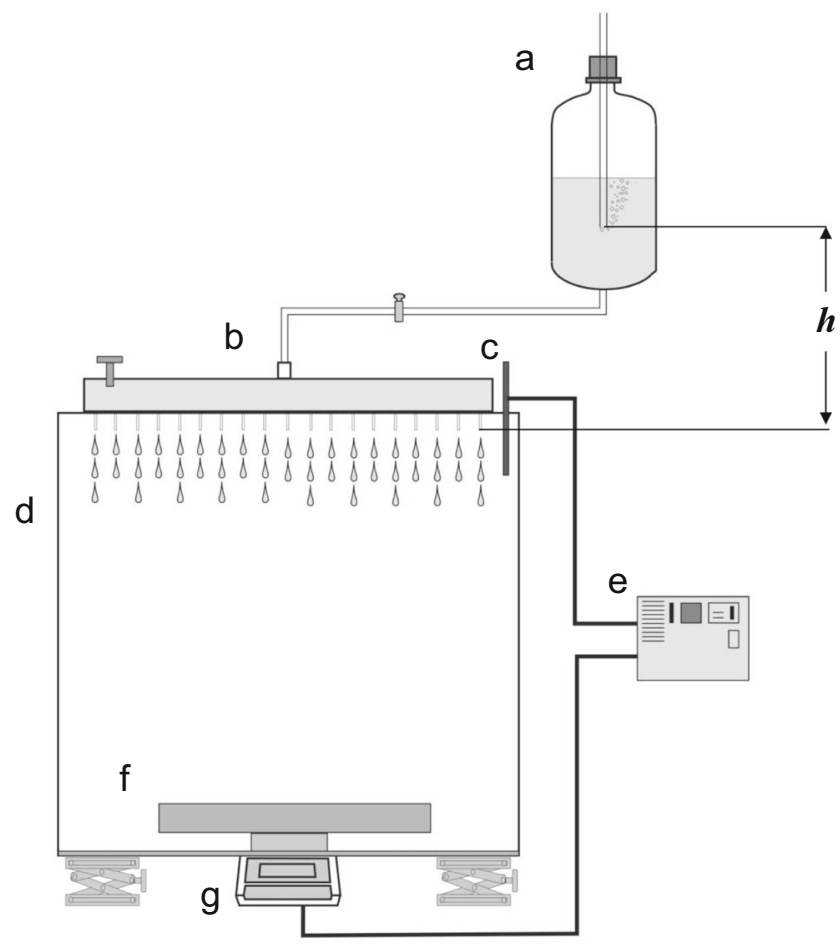

Fig. 3 Experimental setup for the irrigation of pavers. (a) Mariott's bottle, (b) needle irrigator, (c) T, rH probe, (d) hermetically sealed plexiglass box, (e) data logger, (f) paver, (g) balance, (h) the pressure difference, can be adjusted according to the aimed irrigation rate corners. As upper boundary condition, flux rates of 0.007 to $0.6 \mathrm{~mm} \mathrm{~min}^{-1}$ were chosen, encompassing the irrigation rates of the experimental study. The ponding depth before the first runoff occurs was set to $2 \mathrm{~mm}$. The lower boundary was set to no flux boundary, representing the pore discontinuity between paver and construction sand respectively an impermeable bottom. The initial condition was set to $-10^{6} \mathrm{~cm}(\mathrm{pF} 6)$ in the complete profile, representing initially air-dry conditions (50\% relative humidity and $20{ }^{\circ} \mathrm{C}$ ). The simulation depth was $50 \mathrm{~mm}$. All simulations lasted until complete saturation of the material.

\section{Results and discussion}

\subsection{Precipitation event sum and event intensity distributions}

Half of the precipitation in Berlin-Marienfelde (1961-1990, $N$ $=11363$ ) is generated by events with intensities of $p<$ $0.026 \mathrm{~mm} \mathrm{~min} \mathrm{~m}^{-1}$ and with precipitation event sums of $p<$ $4.4 \mathrm{~mm}$ (Fig. 1). The first quartile was found at $p<$ $0.016 \mathrm{~mm} \mathrm{~min}^{-1} ; p<1.8 \mathrm{~mm}$ and the third quartile was at $p$ $<0.06 \mathrm{~mm} \mathrm{~min}^{-1}, p<9.3 \mathrm{~mm}$. These distributions demonstrate the importance of rather small precipitation events for the water balance of Berlin, a city in the temperate region. Analyzing the precipitation distribution functions is crucial for the understanding of runoff and evaporation processes. 
Table 2 Store volume at first runoff $S_{\mathrm{f}}$, the maximum store volume $S_{\mathrm{m}}$, and the store volume at steady-state runoff $S_{\text {eq }}$ as measured in the laboratory experiments for irrigation intensities ranging from 0.015 to
$0.15 \mathrm{~mm} \mathrm{~min}^{-1}$. The numbers in brackets show the standard deviation $(N=6)$. Note that for PP, the stores can be described as a function; the same applies for DP for smaller and for IP for higher rainfall intensities

\begin{tabular}{llll}
\hline Surface store & Dense paver (DP) & Porous paver (PP) & Infiltration paver (IP) \\
\hline$S_{\mathrm{f}}(\mathrm{mm})$ & $0.24(0.08)$ & $f(p)=0.69 p^{-0.29}$ & $1.74(0.16)$ \\
$S_{\mathrm{m}}(\mathrm{mm})$ & $0.36(0.13)$ & $f(p)=0.03 p^{-1.22}$ & $1.92(0.05)$ \\
$S_{\mathrm{eq}}(\mathrm{mm})$ & $0.31(0.11)$ & $f(p)=0.07 p^{-0.86}$ & $1.88(0.04)$ \\
\hline
\end{tabular}

\subsection{Three different stages of surface store filling-dynamic pavement retention}

\subsubsection{Measurements}

In Fig. 4, the results of three of the lab experiments are exemplarily shown. In general, $S_{\text {tot }}$ can be represented by three different store filling stages, according to the rainfall duration and paving material: $S_{\mathrm{f}}, S_{\mathrm{m}}$, and $S_{\mathrm{eq}}$. The first store $\left(S_{\mathrm{f}}\right)$ refers to the start of the runoff from the paver. In the beginning, all the rainwater is retained on and in the paver, and runoff generation starts after a certain time $\left(t_{\mathrm{f}}\right)$. However, the filling process is not finished then but can continue until the maximum water mass is reached which can be kept on the paver $\left(S_{\mathrm{m}}\right)$. This second store is reached when the upper pores and the micro-depressions are filled, often connected with water held by surface tension (Fig. 4). Therefore, this maximum storage $\left(S_{\mathrm{m}}\right)$ at time $t_{\mathrm{m}}$ can be followed by a fast drop in storage, when water drains almost completely from the surface due to the siphon effect. Such behavior was observed for all paver types and all rain intensities. Such draining can lead to different surface storage levels smaller than $S_{\mathrm{m}}$.

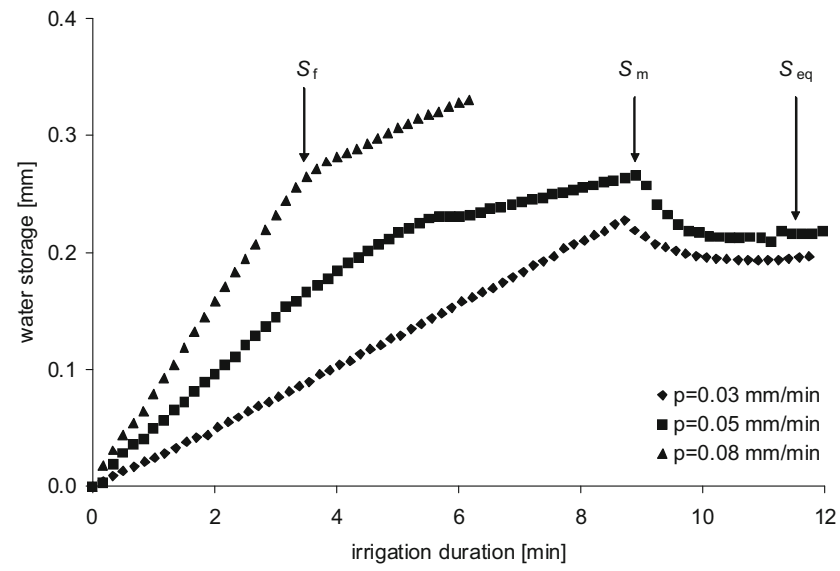

Fig. 4 Water storage exemplary shown for dense pavers (DP) for different constant irrigation intensities. The stores $S_{f}$ storage at the time of first runoff, $S_{\mathrm{m}}$ : maximum storage, $S_{\mathrm{eq}}$ : stored water at steady-state runoff rate are exemplary shown for very prominent examples. Note, that the stores could be identified for all three curves
After that drop, an equilibrium store $\left(S_{\mathrm{eq}}\right)$ is built which is reached at $t_{\text {eq }}$. This third store $\left(S_{\text {eq }}\right)$ then refers to the full amount of pores and/or micro-depressions which are water filled under steady-state runoff conditions.

The dynamics of such surface store filling are highly dependent on material properties but also on infiltration intensity. Not all of these store fillings could be separated in all experiments. Depending on the material (pore system, surface structure) and irrigation intensities, the different stores can be identical $\left(S_{\mathrm{f}}=S_{\mathrm{m}}=S_{\mathrm{eq}}\right)$. This is when the rain intensity is small enough-compared with the conductivity of the material - to fill the pore system completely before the first runoff occurs.

\subsubsection{Simulations}

Figure 5 shows the simulation results for the porous paver (PP) with an intensity of $0.1 \mathrm{~mm} \mathrm{~min}^{-1}$. After less than 20 min, the infiltration sum does not equal rainfall sum anymore. At this time, free water is built up on the surface. Until $t=60$ $\mathrm{min}$, free water is built up on top of the paver and infiltration is

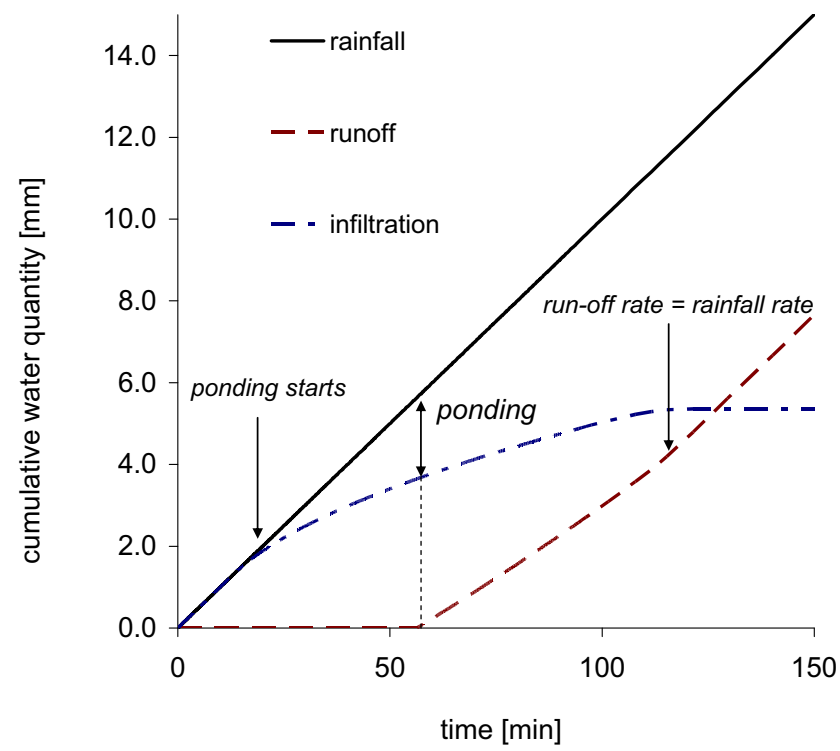

Fig. 5 Filling dynamic of the surface store of the porous paver (PP) as numerically simulated with HYDRUS 1D. Infiltration intensity was $0.1 \mathrm{~mm} \mathrm{~min}{ }^{-1}$. See text for further explanation 
becoming smaller. At $t=60 \mathrm{~min}$, the maximum free water height of $2 \mathrm{~mm}$ is reached and runoff starts. At this time, the store $S_{\text {eff }}$ (cumulative infiltrated water + cumulative amount of water stored on the surface) is approximately $60 \%$ of $S_{\text {eq }}$, which is reached at $t_{\mathrm{eq}} \approx 110 \mathrm{~min}$. Thus, the simulations show that water storage can neither be simply approximated by one of the identified stores $S_{\mathrm{f}}, S_{\mathrm{m}}$, or $S_{\text {eq }}$ nor by a single value below total porosity because the real storage depends on the rainfall intensity (and duration, of course). Note, that the simulations cannot capture the dynamics between $S_{\mathrm{m}}$ and $S_{\text {eq }}$ since the siphon effect is not described by the simulation. The water stored in the paver is thus not $S_{\text {eff }}$ but rather the cumulative infiltrated water at this time because the free surface water will drain if rainfall does not cease before.

\subsubsection{Discussion of the different surface stores}

As analyzed in this study, in Berlin, $50 \%$ of the cumulative rainfall (by event sum) is gained by rain events with an average duration of only $<11.5 \mathrm{~min}$. Measurements and simulations show that $S_{\mathrm{eq}}$ will rarely be reached in reality. Therefore, a better predictor for the surface storage must be defined. Beside of naming one of the identified stores $S_{\mathrm{f}}, S_{\mathrm{m}}$, or $S_{\mathrm{eq}}$, we also suggest to quantify the $S=f(t)$ function (Fig. 5) and to identify $S_{\text {eff }}$ according to the individual question. Apart from the siphon effect, the applied model was appropriate to describe the behavior of water on and in the paver. Having identified the right $S_{\text {eff }}$ from the store filling function, one has to derive the $S_{\text {eff }}=f(p)$ relation from simulation (Fig. 6 a and b) or measurement (Fig. 7a) for the corresponding materials and corresponding range of $p$.

In this study, $S_{\text {eff }}(p)$ can be described as a composite function:

$S_{\text {eff }}(p)= \begin{cases}S_{\text {eff }}=A & \text { for } p<p_{\text {crit }} \\ S_{\text {eff }}=a p^{-b} & \text { for } p \geq p_{\text {crit }}\end{cases}$ where $p_{\text {crit }}$ is the critical rainfall intensity, which is a hydraulic characteristic of the paver that can be identified from measurements or simulation.

Both experiment and simulation have been done with constant rain intensities. However, in the real world, the intensities change during a rain event. This leads to over- and underestimation of the paver storage dynamics. The time to reach $S_{\text {eff }}$ might be overestimated by the experiment as the high rain intensities normally occur at the beginning of real rain events. In turn, the time to reach $S_{\text {eq }}$ was underestimated for some rain events. For instance, for cyclonal rain events, the intensities at the end of rain events are much lower than in the beginning (Rim, 2011). Summing these effects suggest that the generated runoff might occur earlier but its sum at the end of the rain event might be smaller when the rain intensity drops under the actual maximum infiltration rate of the paver material after first wetting. However, this remains speculative and should be evaluated in the following experiments and simulation studies. In the following, $S_{\text {eq }}$ is discussed for the different paving materials, in order to focus on differences between the three materials.

\subsection{Surface stores for three different paver materials}

From the field capacity and the paver dimensions (Table 1), the theoretic pore system stores are calculated: 3.0 for DP, 4.7 for PP, and $1.9 \mathrm{~mm}$ for IP. The surface stores experimentally found are $0.2 \mathrm{~mm}$ for DP, 1.2 to $3.0 \mathrm{~mm}$ depending on $p$ for PP, and 1.8 for IP (Fig. 7a). The reasons for the differences between the pavers and between theoretical storage and experiment are discussed in the following.

For IP, the paver with the highest porosity, only $8 \%$ of the pore volume can hold water against gravity. Furthermore, IP is thin, which leads to a smaller store volume per surface compared with the other pavers. Calculated for the same depths of
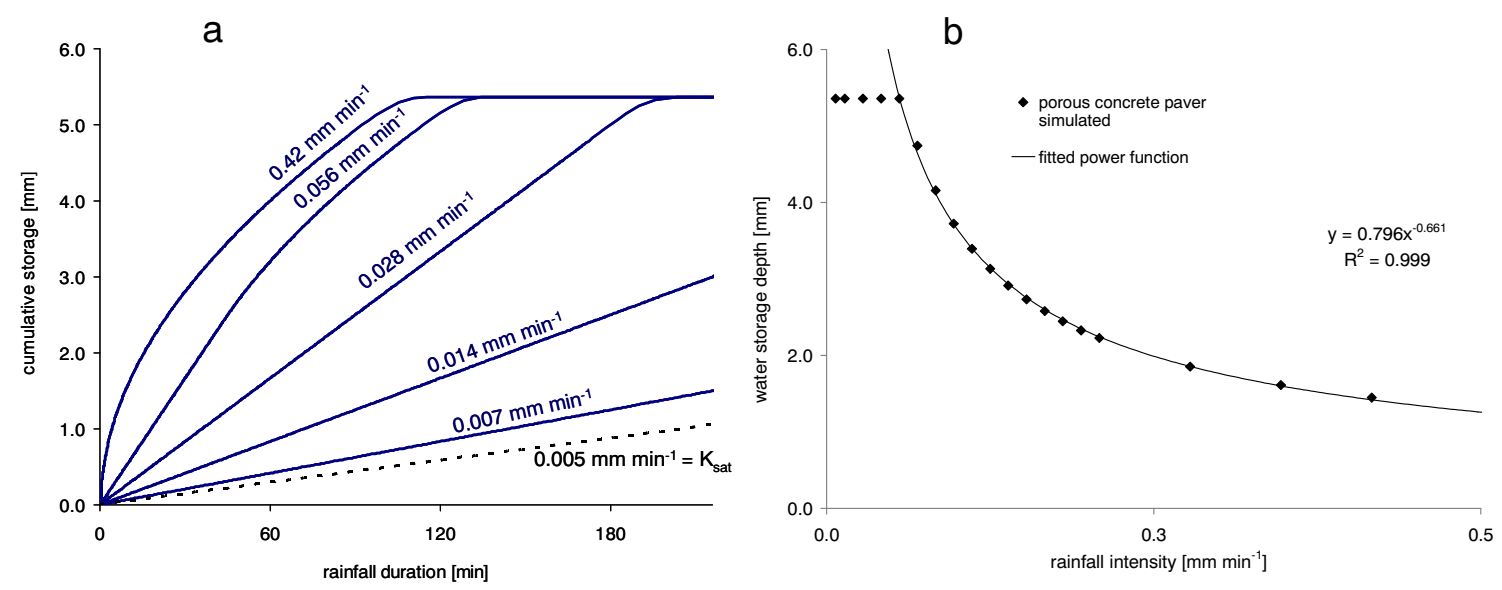

Fig. 6 a Simulated dynamic surface storage filling behaviors for different rainfall intensities indicated by the numbers and the $\mathbf{b}$ derived $S_{\text {eq }}=f(p)$ function. Note that a ponding depth of $2 \mathrm{~mm}$ was simulated on top of the paver 
a

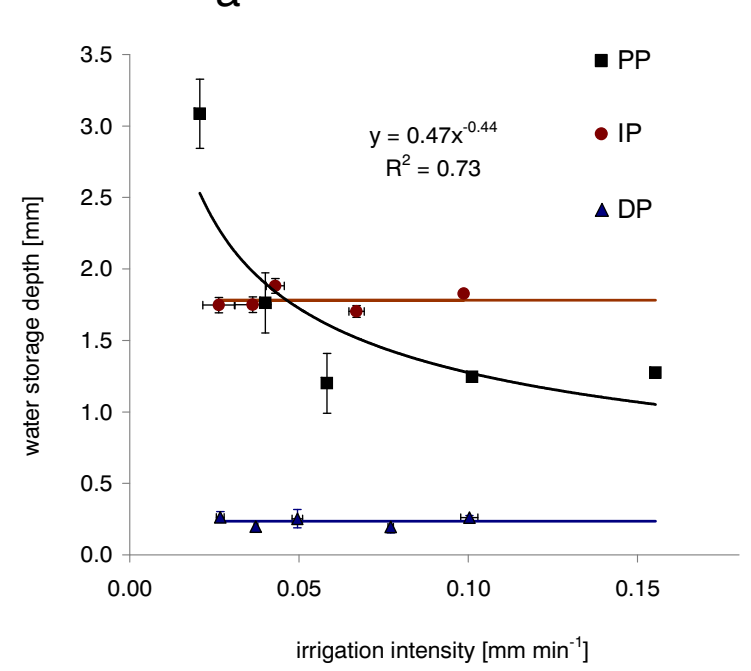

Fig. 7 a Measured dependence of the surface storage from rainfall intensity for porous concrete slabs (PP), dense concrete slabs (DP), and infiltration optimized slabs (IP). Error bars indicate the standard error for the store measurements $(N=3)$. b Schematic dependencies for rather porous pavers, rather dense concrete slabs and slabs optimized for

$50 \mathrm{~mm}$, the water retention at $\mathrm{pF}=1.8$ would be second highest after the PP (Table 1).

For PP, the total porosity is smaller than for IP, but also, the air capacity is smaller, resulting in higher water contents at $\mathrm{pF}$ 1.8. Since no macro-pores are present, the saturated conductivity is also lower than for IP. Due to the small pores, the DP is almost saturated at $\mathrm{pF} 1.8$ and has by far the lowest saturated conductivity $K_{\mathrm{sat}}$ of the tested pavers. This was discussed because the filling dynamic of the pore system of a paver during a rainfall event depends on the development of the infiltration rate $i(t)$ during the rainfall event. The infiltration dynamic $i(t)$ depends on $K_{\text {sat }}$ and the absorptivity or sorptivity of the pavers. The sorptivity is a measure of both the pore characteristics and the initial moisture and can be determined from infiltration experiments according to Philips (1957).

For DP, $i(t)$ is lower than the irrigation intensity $p$ during our experiments. Thus, the pore system of DP cannot store substantial amounts of water under realistic conditions. The filling of the store volume is apparently independent from $p$ in the investigated range (Fig. 7b). We conclude that for dense pavers, not the pore system but the depression store was measured as the apparent surface store. For IP, due to its macropores, $i(t)$ is much higher than $p$ in the investigated range. So here again, the store filling does not depend on $p$ (Fig. 7b). For PP in our experiments, the infiltration rates are in the same order of magnitude as the applied irrigation rates. For low $p$ the infiltration capacity is higher than $p$, for the higher $p$, the infiltration capacity is not sufficient to catch all irrigation water and run-off gets higher. That results in higher store fillings for low $p$ than for the higher $p$ (Fig. 7a, b). b

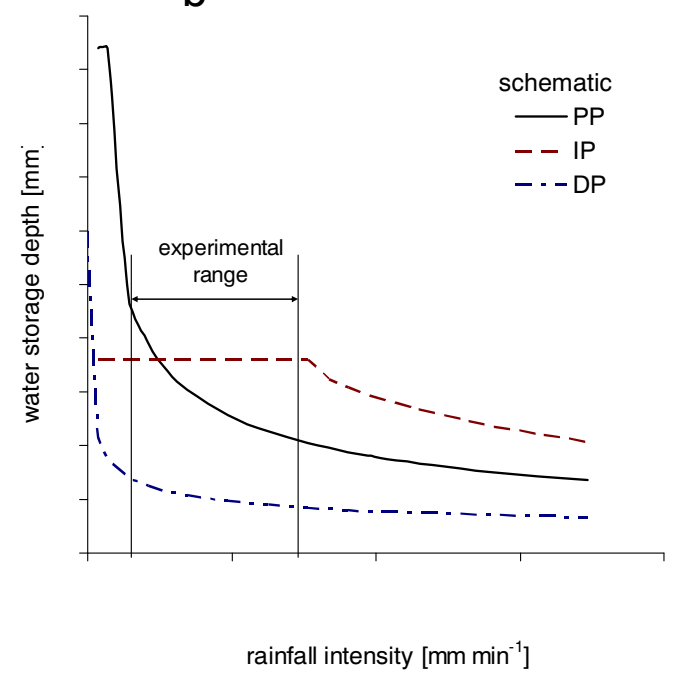

infiltration derived from general theoretical considerations of infiltration into porous media. Note that the three pavers show different parts of the generally likewise curves in the range of rainfall intensities tested in the experiments described in this study.

Both pavers IP and PP could store more water than DP, although less than expected from field capacity (at $\mathrm{pF} 1.8$ ) or porosity. For IP, we observed, during the experiments, that most of the irrigation water drained through the macro-pores. The retained water was stored in depressions at the surface, film water at the macro-pore surfaces, and water which was absorbed from meso- and micro-pores in the matrix, around wetted macro-pores. For the IP pavers, one can expect rising pore system storage with decreasing rain intensity outside the experimental range (Fig. 7b).

For PP, the surface store depends strongly on $p$ for $p<$ $0.06 \mathrm{~mm} \mathrm{~min}^{-1}$ (Fig. 7a). With decreasing irrigation intensity, the porous system can store up to $3 \mathrm{~mm}$ (at $p=0.02 \mathrm{~mm}$ $\min ^{-1}$ ). For $p>0.06 \mathrm{~mm} \mathrm{~min}^{-1}$, the maximum infiltration capacity, which depends on hydraulic properties and initial moisture conditions, is much smaller than the rain intensity. With $1.2 \mathrm{~mm}$ for $p>0.06 \mathrm{~mm} \mathrm{~min}^{-1}$, the surface store of PP is smaller than for IP.

The store of the pore system of pavements is in the same order of magnitude as the depression store on the surface of pavements $(0.7$ to $1.4 \mathrm{~mm})$, directly measured by a terrestrial laser scanner. The investigated pavements were ideally constructed, without puddles and irregularities (Nehls et al. 2015). Both stores can theoretically add up to about $4.5 \mathrm{~mm}$. Even then, only stores of ideal pavements are considered; the stores of real pavements, with depressions, cracks, and puddles, are not studied yet.

In this study, the irrigated pavers have been horizontally aligned, even though pavements are often inclined to $\approx 2^{\circ}$ in practice to prevent ponding waters. We stuck to the simple 
horizontal setup to focus on the more fundamental question of how much water the different pavers can store under different irrigation regimes. Moreover, for the results of our experiments, an inclination of $2^{\circ}$ would be of little importance, as it influences rather $S_{\mathrm{m}}$ than $S_{\text {eq. }}$. However, for very high irrigation intensities, when $p>>$ infiltration capacity, the slope might play a role in the effective surface storage. This topic is beyond our current study but points to a further research question.

Comparing the hydraulic properties of pavers with underlying urban soils substrates, the following can be stated: field capacities (at $\mathrm{pF} 1.8$ ) for soil texture classes vary from $0.1 \mathrm{~m}^{3}$ $\mathrm{m}^{-3}$ for heavily compacted sand to $0.5 \mathrm{~m}^{3} \mathrm{~m}^{-3}$ for a noncompacted clay (Ad-Hoc-AG Boden, 2005, table 70) not considering soil organic matter. Thus, for their field capacity, the pavers are similar to heavily compacted pure sand. The saturated hydraulic conductivity $K_{\text {sat }}$ for soil texture classes varies from $0.014 \mathrm{~mm} \mathrm{~min}^{-1}$ for heavily compacted clays to more than $2.6 \mathrm{~mm} \mathrm{~min}^{-1}$ for loose sand. Thus, according to their $K_{\text {sat }}$, DP and PP pavers have 14 times respectively 3 times smaller conductivity compared with soils, while IP pavers, due to their coarse pores, have a much higher conductivity than soils.

\subsection{Effectiveness of surface storage and evaporation}

The surface storage in and on pavers governs the water balance of paved urban soils to a certain extent. First, for a given store, only a part of the rain events can be retained completely. Second, the storage itself depends on the rain event intensity. Both factors influence the effective store and can be described by means of the rain event intensity and rain event sum distribution function for a specific climate in the world (Fig. 8). Based on that distribution function, the number of intercepted rain events and their contribution to the cumulative rain event sum can be calculated for the stores. For the DP, $1.6 \%$ of the cumulative rain event sum can be intercepted (2362 events), for the IP, it is $25 \%$ ( 8729 events). Considering only the static storage of $1.2 \mathrm{~mm}$ PP can intercept 18\% (7779 events) of the cumulative rain event sum. If the dynamic storage of PP is considered, that amount doubles (35\%, 9418 events).

Obviously, a comparison like given in Fig. 8 can only give a general overview which can be understood as a potential rain interception. To calculate the actual rainwater storage and the actual evaporation from that storage, one has to consider a set of boundary and initial conditions which govern the process such as temporal rainfall distribution, the antecedent storage filling (initial moisture), and potential evaporation. Apart from that, the result of a water balance simulation for the surface is also very sensitive to the chosen temporal resolution. The higher the rainfall boundary condition is smoothed as compared with the real rainfall distribution, the higher is the risk to overestimate the evaporation. An even distribution of rainfall

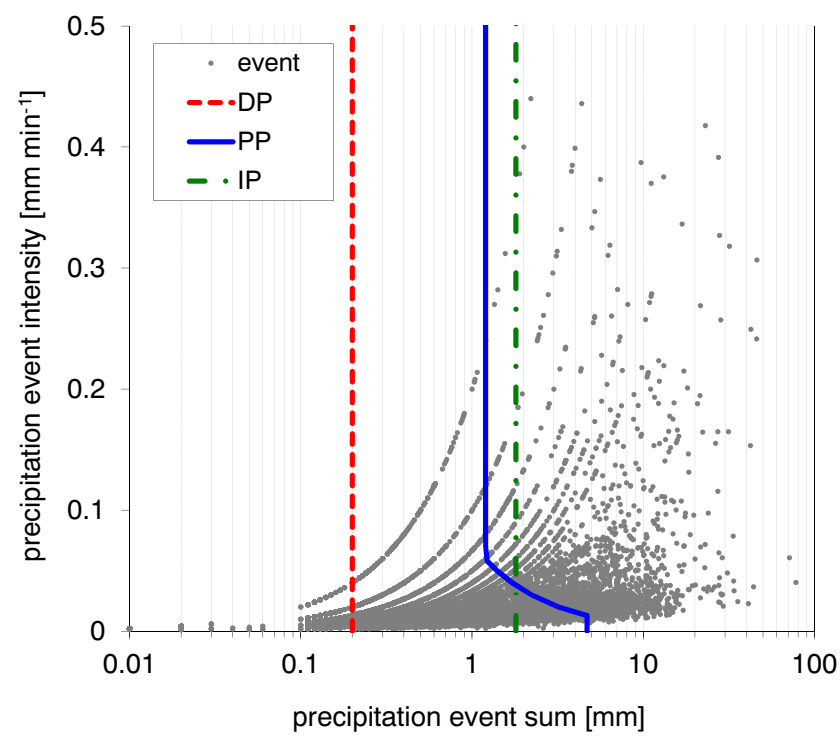

Fig. 8 Surface store of the three different paver types of porous paver (PP), dense paver (DP), and infiltration optimized paver (IP) in relation to rain event's intensities and rain event sums in Berlin, Germany

during the day can lead to a cumulative actual evaporation higher than the store for potential evaporations higher than the storage (typical in summer). The more the distribution of real rainfall events is aggregated for the boundary condition, the higher is the risk to underestimate the evaporation from pavements. Both uncertainties sum up for long time series. As for many applications (e.g., evaporative cooling for heat stress mitigation) dynamics are of high interest, we encourage simulating water balance processes in urban areas with the highest possible temporal resolution and using all available information on surface characteristics including pavement materials and surface micro-morphology.

\section{Conclusions}

The pore system of paving materials (material characteristics) contributes to the total surface store of pavements to the same extent like the storage of free water in depression volumes on the surface of the pavement system (design characteristics). Given the water retention function and the saturated conductivity of the materials, the dependency of the surface store from the rainfall intensity can be calculated.

Pavement materials can evaporate a multiple of their surface store, depending on the rainfall distribution. This and the rainfall rate dependence of the surface store of the pavers suggest modeling of evaporation and rainfall-runoff partitioning with high temporal resolution. Otherwise, the runoff is either overestimated and evaporation is underestimated or vice versa. This must be considered in simulations of urban heat stress and adaptation strategies. 
Our findings also imply a rainfall intensity dependence of the runoff coefficient and therefore suggest no longer using the concept of constant runoff coefficients.

Authors' contributions All authors contributed to the study conception and design. Material preparation, data collection, and analysis were performed by Thomas Nehls, Fabian Kraus, and Yong Nam Rim; model setup and simulations were done by Andre Peters and Thomas Nehls. The manuscript was written by Thomas Nehls and Andre Peters and all authors commented on previous versions of the manuscript. All authors read and approved the final manuscript.

Funding information Open Access funding provided by Projekt DEAL. We cordially thank the German Science Foundation (DFG FOR 1736 "Urban Climate and Heat stress") and the BMBF (FKZ 033W103G Blue Green Streets) for funding.

Open Access This article is licensed under a Creative Commons Attribution 4.0 International License, which permits use, sharing, adaptation, distribution and reproduction in any medium or format, as long as you give appropriate credit to the original author(s) and the source, provide a link to the Creative Commons licence, and indicate if changes were made. The images or other third party material in this article are included in the article's Creative Commons licence, unless indicated otherwise in a credit line to the material. If material is not included in the article's Creative Commons licence and your intended use is not permitted by statutory regulation or exceeds the permitted use, you will need to obtain permission directly from the copyright holder. To view a copy of this licence, visit http://creativecommons.org/licenses/by/4.0/.

\section{References}

Ad-Hoc-AG Boden (2005) Bodenkundliche Kartieranleitung. Schweizerbart'sche Verlagsbuchhandlung, Stuttgart, Germany (official German field guide for state soil surveys)

Deutscher Wetterdienst DWD, Frankfurter Straße 135, 63067 Offenbach, Germany

Fayer MJ, Simmons CS (1995) Modified soil water retention functions for all matric suctions. Water Resour Res 31(5):1233-1238

Field R, Masters H, Singer M (1982) An overview of porous pavement research. Water Resource Bul 18(2):265-270

Goebel P, Dierkes C, Kories H, Messer J, Meissner E, Coldewey WG (2007) Impacts of green roofs and rain water use on the water balance and groundwater levels in urban areas. Grundwasser 12:189200

Heinzmann B (1998) Improvement of the surface water quality in the Berlin region. Water Sci Technol 38:191-200

Iden SC, Durner W (2014) Comment to "Simple consistent models for water retention and hydraulic conductivity in the complete moisture range" by A. Peters Water Resour Res 50:7530-7534. https://doi. org/10.1002/2014WR015937
Jarvis NJ (2007) A review of non-equilibrium water flow and solute transport in soil macropores: principles, controlling factors and consequences for water quality. Eur J Soil Sci 58:523-546

Mansell M, Rollet F (2009) The effect of surface texture on evaporation, infiltration and storage properties of paved surfaces. Water Sci Technol 60:71-76

McGraw-Hill Dictionary of Scientific and Technical Terms (2002) Sixth ed. McGraw-Hill Professional, New York

Mualem Y (1976) New model for predicting hydraulic conductivity of unsaturated porous-media. Water Resour Res 12:513-522

Nakayama T, Fujita T (2010) Cooling effect of water-holding pavements made of new materials on water and heat budgets in urban areas. Landsc Urban Plan 96(2):57-67

Nehls T, Jozefaciuk G, Sokolowska Z, Hajnos M, Wessolek G (2008) Filter properties of seam material of paved urban soils. Hydrol Earth Syst Sci 12:691-702

Nehls T, Nam Rim Y, Wessolek G (2011) Technical note on measuring run-off dynamics from pavements using a new device: the weighable tipping bucket. Hydrol Earth Syst Sci 15(5):1379-1386

Nehls T, Menzel M, Wessolek G (2015) Laser scanning based measurement of depression store of paved urban areas and its relevance for evaporation. Water Sci Technol 71(6):862-869

Oke TR (1982) The energetic basis of the urban heat-island. Quarterly J Royal Meteorol Soc 108:1-24

Peters A (2013) Simple consistent models for water retention and hydraulic conductivity in the complete moisture range. Water Resour Res 49:6765-6780

Peters A (2014) Reply to comment by S. Iden and W. Durner on "Simple consistent models for water retention and hydraulic conductivity in the complete moisture range". Water Resour Res 50:7535-7539

Peters A, Durner W, Wessolek G (2011) Consistent parameter constraints for soil hydraulic functions. Adv Water Resour 34(10):1352-1365

Philip JR (1957) The theory of infiltration: 4. Sorptivity and algebraic infiltration equations. Soil Sci 84:257-264

Ramier D, Berthier E, Dangla P, Andrieu H (2006) Study of the water budget of streets: experimentation and modeling. Water Sci Technol 54(6):41-48

Rim, Y N (2011) Analyzing runoff dynamics of paved soil surfaces using weighable lysimeters. Doctoral Thesis, Technische Universität Berlin. online: https://depositonce.tu-berlin.de/handle/11303/3123

Simunek J, van Genuchten MT, Sejna M (2008) Development and applications of the HYDRUS and STANMOD software packages and related codes. Vadose Zone J 7:587-600

Starke P, Goebel P, Coldewey WG (2010) Urban evaporation rates for water-permeable pavements. Water Sci Technol 62(5):1161-1169

Vogel T, van Genuchten MT, Cislerova M (2001) Effect of the shape of the soil hydraulic functions near saturation on variably saturated flow predictions. Adv Water Resour 24:133-144

Wessolek G, Facklam M (1997) Standorteigenschaften und Wasserhaushalt von versiegelten Flächen. J Plant Nutr Soil Sci 160(1):41-46

Publisher's note Springer Nature remains neutral with regard to jurisdictional claims in published maps and institutional affiliations. 